\title{
Teaching Reform and Practice on the course of Webpage Design and Making Based on Computational Thinking
}

\author{
WeinaZhang \\ Computer NIC Center \\ Communication University of China \\ Beijing, China \\ zhangweina@cuc.edu.cn
}

\author{
HaiboWang \\ Computer NIC Center \\ Communication University of China \\ Beijing, China \\ wanghb@cuc.edu.cn
}

\begin{abstract}
In order to better cultivate university students' ability of solving problems by computer, computational thinking is demanded during the computer fundamental teaching. Web design and making is one of university computer fundamental courses. Computational thinking is introduced to the course and impenetrates the whole teaching process ,so that it not only makes students learn how to design and make webpage but also makes them understand the essence of computer ,experience the joy of learning computer and explore resolution of actual problem by computer. Teaching practice shows that teaching reform based on computational thinking improves students' interesting and teaching effect to some extent.
\end{abstract}

Keywords- webpage design; Webpage making; computational think; teaching reform

\section{INTRODUCTION}

With the development of Internet, Webpage is becoming important carrier of information. Mastering fundamental knowledge of webpage design and making not only enables students to make better use of network to solve problems in study and work but also is one of the basic requirements of using computer ability in "One Body Two Wings" teaching philosophy. Webpage design and making is a course closely integrated theory and practice. As a university education should not only teach some fundamental concepts and some application software operation, but also cultivate computational thinking ability, so that students can learn to think and solve problems like a computer scientist [1].

There are following problems in classic teaching method and content of Webpage design and making course. (1)Teach scattered knowledge, as a result students do not know how to apply their knowledge to solve specific problems. (2)Teaching the course purely as a tool results in students can only operate the software not solve practical problems.(3) Teaching content is outdated and it does not reflect the industry's new technology and new ideas.

Computational thinking will help people solve the problems of their respective fields by computer. University stage is the best stage of systematic and theoretical training thinking, so computational thinking is closely related with reforms of university teaching [2].

Combining with years of front-line teaching experiences and consulting website designers, we adopt new teaching model in actual teaching process. The model is based on computational thinking and adopted task-driven approach. It is helpful for cultivating students' ability of solving complex problems by flexibly using their knowledge and innovation ability [3].

\section{TEACHING CONTENT}

\section{A. Organize Teaching Content in terms of Problem Solving}

Teaching content is designed according to the actual website development process and the required knowledge and skills. Website development process is as figure 1.

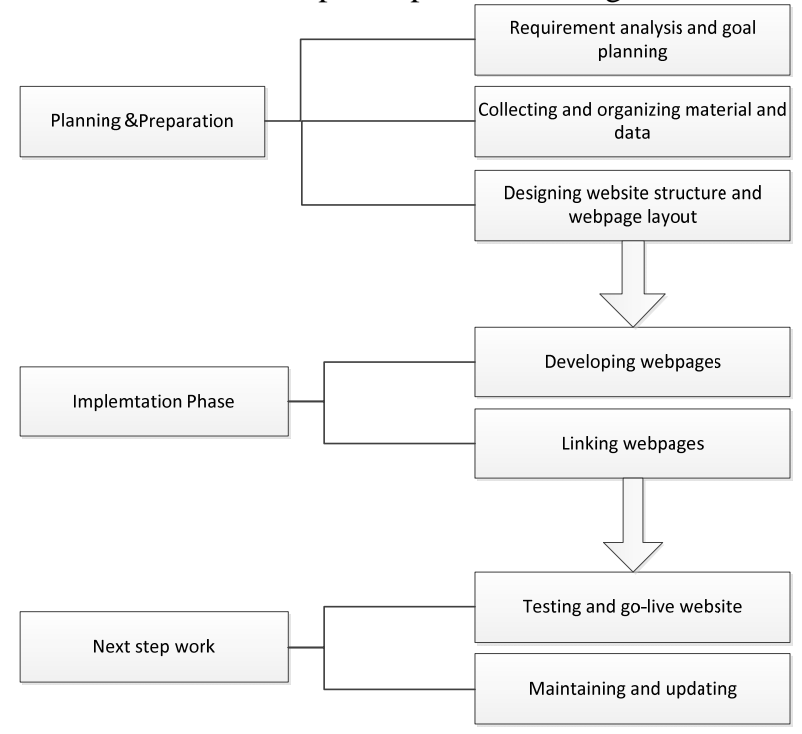

Figure 1. Website development process

The course content is assigned in accordance with the above process. There are the fundamental knowledge of website design, tool (such as Dreamweaver) commonly used for developing webpage, fundamental knowledge of HTML, the approach to laying out and developing webpage such as table layout, frame layout, DIV + CSS layout, the creation and application of CSS style, the application of JavaScript, Fundamental knowledge of dynamic webpage design and go-live and maintenance of the website. Because the course 
is set up for non computer majors and has no much time, the dynamic webpage design content is less.

\section{B. Follow and Study New Technology and Update Teaching Content Timely}

According to the development of webpage design technology, the course timely removes old contents and adds new contents. Take an example of the method of page layout. Previously, more website is designed by the table layout .Its advantage is simple and intuitive, but the drawback is mixing content and form together. It is not convenient for website revision and maintenance. Recently, DIV + CSS layout is increasingly popular, using the layout not only make the page more expressive, but also separate forms and content. It is convenient for website revision and maintenance. So we gradually spread the explanation of the layout in recent course content. The teaching content strives to keep pace with new technologies and new ideas in the field.

\section{The Contents of Experiment Consolidates and Supplements Classroom Teaching}

Because of classroom time is limited, it is impossible teacher teach every detail in class. So experiment content supplements the content of classroom teaching in actual teaching practice. The contents of experiment include fundamental knowledge, fundamental operation, operation skills and thinking questions. The fundamental knowledge and operation consolidate and supplement the classroom content. Operation skills provide some operation methods for students. Thinking questions help students further understand the link between classroom content and relevant knowledge.

\section{TEACHING METHOD}

Teaching method emphasizes training students’ practical and thinking ability. It reflects the charm and basic methods of computational thinking through the reform of teaching method [4].

\section{A. Use Task-driven teaching method}

To establish the problem oriented task-driven teaching method can better adapt to the learning and thinking training purpose. Task-driven teaching method is a kind of students' inquiry learning teaching method. It pays attention to the autonomy of the students and interactivity between teachers and students. In the teaching process, students are centered teachers assigning task and guided teachers designing questions. Then they think positively and ultimately solve the problem. The students thinking can get effective training during the process of inquiry learning based on completing the task and solving the problems [1].

This course requires students to complete a certain workload theme website after a semester. In order to make students understand the teaching task, teachers present and analyze typical works in first class. The works involve teaching website by teachers own, previous students' excellent works, as well as website running on the Internet. Each case guides and inspires students in different aspects. Teaching website has clear theme and modules. It helps students know the technologies which will be learned and how to use them. Presenting excellent works can help students to enhance confidence to complete study task and improve their learning enthusiasm. The analysis of actual site helps students to know the newly design idea and technologies. Practices in recent semesters show it helps students clear their learning objectives and improve their learning enthusiasm. In Each class students must finish the part of planning website according to teaching content. They must finish the website by the end of semester. The taskdriven teaching method is helpful to improve students' ability of analyzing and solving problems.

\section{B. Clear the Overall Goal, Decompose and Implement Phase Goals}

Determine the overall goal beginning with solving system problems. The overall goal is decomposed and implemented in each class. Computational thinking is using abstraction and decomposition when attacking a large complex task or designing a large complex system. It is separation of concerns [5] [6].

In terms of computational thinking, overall teaching goal and basic flow of designing website, teachers assign every class subtask. Each subtask is relevant with the class content. For example, students are required to complete some column of their theme website with layout method referred in class after they learnt how to layout webpage. After they learnt CSS (Cascading Style Sheets), they are required to beautify their own webpage with CSS. Completing each task not only make them consolidate classroom knowledge but also make them feel accomplishment and satisfaction. Thus they are from the "want me to learn "to "I want to learn" and their initiative is improved [7].

\section{Use the Heuristic Teaching}

Computational thinking is using heuristic reasoning to discover a solution. It is planning, learning, and scheduling in the presence of uncertainty[5][6]. According to the theory of computational thinking, the case which is selected and taught is no more teach students some operation skills and solutions than make students know the method of solving problems which implied the case. Take an example of validating form with JavaScript. Firstly, we expose a question that how to ensure the inputted information validate? Secondly, we analyze how to solve the problem in actual website such as 163 mailbox. Thirdly, we propose the solution involving script language. Finally, we complete the case with JavaScript. After-school we require students to complete validating their form in their theme website.

Take another example of teaching CSS. Firstly, Teacher presents some questions. For example, How to implement same style such as same font style ,same background and so on in several parts of a page or in several pages conveniently? How to quickly change the old style? Secondly, we propose several alternatives, and compare their advantages and disadvantages. Thirdly, we inspire students through the review of the Word style. Finally, we implement webpage style by CSS. Then we conclude the advantages of CSS. Thus, Students can deeply understand the function of CSS and flexibly apply CSS in the webpage making. 
The heuristic teaching method is helpful for developing students' initiative and improving the students' listening attention.

\section{Take Effective Assessment Methods, Comprehensive Evaluate Learning Effects}

The course is closely integrated theory and practice, so we need comprehensively assess students from fundamental theory to practical operation ability. In teaching practice, in addition of completing a theme website during the semester, we exam the students with objective and operation tests in final examination. Objective questions test students' mastery of the fundamental concepts and operation questions test their operation ability. Practices show that the assessment can assess them comprehensively.

\section{TEACHING MEANS}

\section{A. Adopt an Effective Tool for Analyzing the Technology Used in the Actual Pages}

Analyze webpages by Firefox + Firebug + Web Developer in actual teaching. Firebug and Web Developer are a plug-in installed in the Firefox browser. The plug-ins can assist users in analyzing the webpages. As shown in Figure 2, analyze pages structure by Firefox.

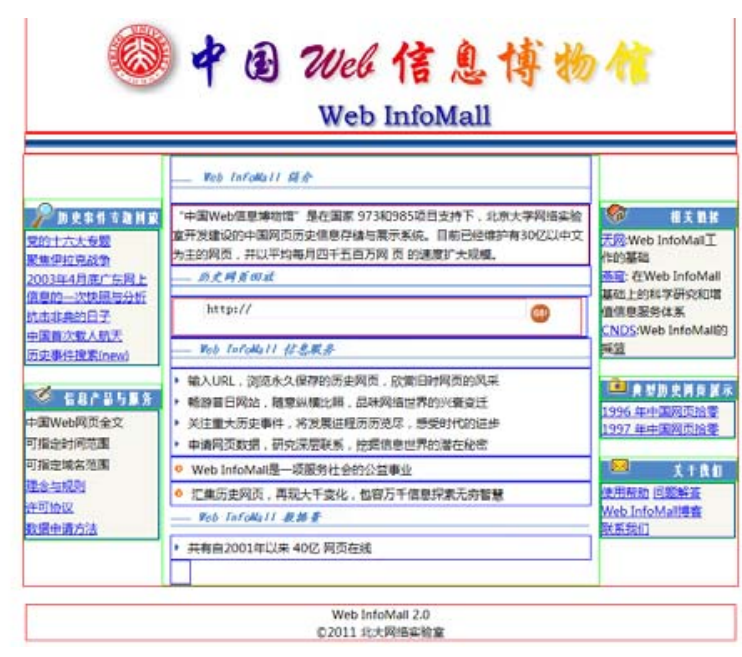

Figure 2. Web InfoMall page structure

By analyzing webpages in actual website, students not only know how to lay out webpage but also learn how to use the tools for learning.

\section{B. With the Aid of the Network Platform Realize the Interactive Teaching and Achieve Random Access Instruction.}

In actual teaching, it is impossible that all students can grasp the content which teacher speaks in the classroom. They need review it after class. In order to make students better review, we upload coursewares and the corresponding learning materials to teaching website, students can access and download them at any time. In addition, offer corresponding BBS (Bulletin Board System) in website, students and teachers can discuss questions each other and share resources.

\section{FURTHER DISCUSSION ON TEACHING REFORM}

Now we add computational thinking to students' analytical ability by method-driven [4]. The course content is not big adjustment. We guide students to realize computational thinking disciplines and characteristics of knowledge behind it through adjusting teaching method. We need further summarize students' teaching evaluation and suggestions. Then we organize the teaching content based on computational thinking and further modify course content structure so that teaching is more conducive to cultivating students' computational thinking ability.

\section{CONCLUSION}

In recent years, we adopt the reform and the practice referred in paper during the teaching process. Practices show that the methods inspire students' interest and learning initiative and improve the teaching effects. Most students can independently complete a theme site and some students apply in cyberspace and upload their own works by the end of semester. Now, students' work quality is better than the previous students'.

In the future teaching work, we need further explore on the teaching methods, teaching content, assessment methods.

We not only focus on the research and apply tools, but also pay attention to the impact of tool research for thinking. Consciously use growing wealth of scientific thinking to promote scientific technological development and social progress [8].

\section{REFERENCES}

[1] YiSheng qiu,Peng Guo xing,Liu Qiang.Study of the Teaching Reform of University Computer Fundamental Course. Enterprise Science And Technology \& \& Delopment,Practice\& Innovation,No.19,2012(Cumulatively NO.337).

[2] WANG Wenming, TAN Yuan. Several problems of the teaching reformation based on Computatoinal Thinking.Software.No.8,vol.33,2012.

[3] GuoLi,YeHuiWen. Construction and application of TPBIM in the pilot course of" the reform of public computer courses in colleges and universities of Guangdong Province ", China Educational Technology.Dec.2012(Cumulatively NO.311).

[4] FengBoQin.Discussion on the issue of implementing cultivation computational thinking ability , China University Teaching.No.9,2012.

[5] ChenGuoLiang, DongRongSheng.Computational Thinking and University Computer Fundamental Education. China University Teaching,No.1,2011.

[6] Jeannette M. Wing. Computational Thinking. Communications of The ACM. Vol.49,No.3,March 2006.

[7] FanHaiBo. The Application of the Participatory Teaching Method in Teaching. Northern Economy and Trade, NO.3,2009.

[8] TanHaoQiang.Research on Computational thinking, Adhere to the Application-oriented.Computer Education, No.21, Nov.2012. 